\title{
Hub of medical expertise or medicalised conveyor-belt? Sharing meanings online on the hospital birth setting
}

\author{
Antoinette Fage-Butler (Aarhus)
}

\begin{abstract}
In 2014, the official risk advice in the UK regarding birth setting was altered given scientific evidence that for low-risk groups, home births are safer than hospital births. As hospital births were previously the de facto recommendation, and pregnant women in the UK now need to consider their birth setting options carefully, many go online, seeking advice about birth setting options from their peers. In this paper, I investigate how the hospital birth setting is constructed on an online forum where women seek advice on the relative merits of various birth settings, analysing posters' constructions of the hospital birth setting using Foucauldian discourse analysis. Findings reveal that the hospital birth setting is characterised either as the best and safest place to ensure safe delivery due to on-site biomedical experts and technology, or it is constructed as dehumanising, involving unnecessary intervention-related risks to mother and baby. The majority of the threads are critical of the hospital birth setting. Besides these findings, this paper contributes methodologically to the study of birth settings as it adopts a cultural approach supported by discourse analysis, illustrating the metapragmatic context within which birth setting decisions are made. As women's perspectives on the birth setting issue are in focus, findings regarding women's satisfaction with the various options are valuable for healthcare professionals who support women with birth setting decisions, as well as obstetric and maternity practitioners in the hospital setting. The extent of posters' critique of the hospital birth setting suggests the need for further research.
\end{abstract}

\section{$1 \quad$ Introduction}

The most commonly chosen birth setting in the UK is the hospital obstetric unit with, for example, $87 \%$ of women in England giving birth in hospital obstetric units in 2012, $9 \%$ in midwifery units situated on the same site as an obstetric unit, $2 \%$ in freestanding midwifery units, and $2 \%$ at home (Department of Health 2013). Although hospital obstetric units have been promoted for many decades as the safest and most responsible birth setting (Armstrong 2010; Coxon/Sandall/Fulop 2014; Nolan 2015), the National Institute for Health and Care Excellence (NICE), which provides independent, authoritative health advice in the UK, recently recommended home birth as the optimal choice for women at low risk of complications (NICE 2014), given evidence of its safety for low-risk groups (Brocklehurst et al. 2011). As this advice partly repeals or heavily qualifies previous risk guidance where hospital births were promoted as the best, safest birth setting option, pregnant women in the UK now find 
themselves at a decision point regarding where to give birth where the stakes seem very high - nothing less than the safe delivery of their babies, as well as the personal riskiness of potentially making a bad decision (Striley/Field-Springer 2016). Given the instability of medical advice on birth setting and the challenges involved in deciding where to give birth, many women seek the experiential knowledge (Caron-Flinterman/Broerse/Bunders 2005) and perspectives of their peers online. This is in line with previous research that indicates that people use online health forums for reasons such as gaining knowledge and support from their peers (Fage-Butler/Nisbeth Jensen 2012) and seeking advice (Locher 2010; Morrow 2006).

Previous research on birth settings has focused to a large extent on the relative riskiness of the various birth settings for neonatal outcomes and breastfeeding rates (e. g. Akrich et al. 2014; Zielinski/Ackerson/Low 2015). However, as the birth setting decision is complex, situated and personal, it is also important to identify the personal experiences and predilections, as well as cultural associations that play a role in the birth setting decision. Women's birth setting decisions have mainly been investigated using interviews (e. g. Brailey et al. 2015; Wood et al. 2016), with a shortage of other methodologies being evident. Not only this, but the socially exchanged meanings that have coalesced around the discursive "object" (Foucault 1972: 40) of the hospital birth setting have not been sufficiently explored (Jha et al. 2008; Reyniers et al. 2014). However, there is growing awareness that "Place and space is [sic!] not neutral. [...] [S]pace shapes our being" (Kenkmann et al. 2017: 8), and Andrews (2016: 272) observes that place is a "complex socio-cultural construction, experience, and phenomenon", whilst others have underlined the importance of "therapeutic landscapes" (Burges Watson et al. 2007; Gesler 1992). Given the recent changes in risk guidelines regarding birth settings and the aforementioned gaps in the literature, the purpose of this paper is thus to investigate how posters in an online forum of a British-based parenting website discursively construct the hospital birth setting. Investigating discursive constructions of the hospital birth setting helps to expose some of the cultural parameters of the birth setting debate (Coxon 2014).

Discursively, the data investigated in this paper reflect the polarisation in the debate (hospital vs. home birth setting), and posters who respond to queries about their experiences of and perspectives on these systems tend to highlight the grounds for their satisfaction or dissatisfaction with the various birth settings. The valorised, affective nature of the posters' comments is certainly important. Women's satisfaction with birth setting matters, as poor birth experiences can lead to long-term health consequences such as lower maternal satisfaction and confidence (Maehara et al. 2016: 20). Sawyer et al. (2013: 637) elaborate on this point as follows: "dissatisfaction [with care during childbirth] is associated with poorer postnatal psychological adjustment, a higher rate of future abortions, preference for a caesarean section, more negative feelings towards the infant, and breast-feeding problems". Given the health implications of (dis)satisfaction with birth experiences, Srivastava et al. (2015) emphasise the importance of feedback, where women's views about their maternity care are ascertained and incorporated into quality assessments of care services, and help improve the quality of future service provision. Moreover, it appears a truism that health care cannot be deemed to be high quality unless individuals are satisfied with the care they receive (Mahon 1996). This paper sheds important light on women's personal experiences of and attitudes to the hospital birth setting. It identifies aspects that, from the users' perspective, contribute to satisfaction and 
dissatisfaction with the hospital birth setting, as well as indicates how satisfaction and dissatisfaction with the hospital birth setting are discursively legitimised.

\section{$2 \quad$ Data and methodology}

The present paper contributes methodologically to the exploration of satisfaction with birth settings. Methods of data generation used to establish satisfaction with maternity care typically involve questionnaires and surveys (Bélanger-Lévesque 2014; Truijens et al. 2014), but there are methodological issues such as the "halo effect" (Sawyer et al. 2013: 641) where women, who have been helped through difficult birth scenarios, such as preterm deliveries, exhibit a less critical attitude to the services provided. Van Teijlingen et al. (2003: 80) have criticised a general reliance on quantitative surveys, stating that "we should not assume that we know what women's needs are from the results of satisfaction surveys", promoting instead the idea that surveys should be triangulated with other methods. In that regard, it is relevant that Redshaw (2008: 73) notes that qualitative data regarding women's maternity care can provide "a more complex picture of women's experience"; she recommends exploring issues relating to "dissatisfaction" as much as "satisfaction" to ensure better coverage of negative experiences. The data analyzed in this paper have the advantage of being "authentic" as they were not produced for the purposes of research; rather, they reflect the feelings and opinions about the hospital birth setting that women share with their peers, where there is at least as much emphasis on dissatisfaction as on satisfaction. As the online data examined in this study were produced "in the wild" (Jones 2013: 88) in authentic exchanges, this also minimises the likelihood of social desirability bias that can affect the quality of interview studies (Coulson 2015: 134-135), particularly when the topic is controversial or sensitive (Collins/Shattell/Thomas 2005; Krumpal 2013). Moreover, the online setting facilitates the expression of opinions beyond the mainstream (Cohen/Raymond 2011), which is particularly valuable for the birth setting issue where a high degree of moralising about the mother's responsibility to do what is right for her unborn baby is prevalent (Coxon/Sandall/Fulop 2014; de Crespigny/Savulescu 2014; Lupton 2013).

The data that were analyzed in this study are drawn from an online forum on a popular British parenting website, consisting of threads that were initiated with posters' open-ended questions about the relative merits of choosing home birth or hospital birth. The data are freely available without password protection, and posters are reminded that anything they post is in the public domain. However, as an extra safeguard, I followed the British Psychological Society's (2013) guidelines on ethical online research by restricting details that might identify the forum, correcting typos, writing abbreviations out in full, and omitting shorter sections with [...] to make it difficult to trace with search engines.

In March 2016, I used the search function on the website to identify all 440 threads that included either the key term homebirth or home birth. To ensure that home birth was in focus and not just mentioned in passing, I used Kouper's (2010) typology of advice solicitations, including threads in the final data set only if the opening entry in the thread included an explicit request for advice regarding the choice of home birth over hospital birth or an explicit request for opinions on or information about the home birth option. This resulted in a data set of 18 threads created between 2010 and 2015, initiated by 18 different posters and altogether 
consisting of 1162 posts. To the best of my knowledge, the threads were initiated by pregnant women facing the personal predicament of whether to choose home birth or not; however, as the participants used pseudonyms for their online identities, there was no way of checking this.

The asynchronous online forum from which the current data were gathered did not allow for social media-like interaction such as "likes", and images were not used within the content of the posts. Instead, user-generated content was possible either by posters adding a new post to create a new thread, or by posting a comment to an existing thread. However, the affordances of online forums, which include metavoicing (reacting to others' content), triggered attending (for example, in response to an alert), network-informed associating (developing relational and content ties) and generative role-taking (facilitating dialogue) (Majchrak et al. 2013) allow for the development of "opinion leaders and valued experts" (Majchrak et al. 2013: 48), making the discourse of online health forums, such as the present, particularly relevant to study when competing knowledges and perspectives are at stake.

Investigations have shown that forum participants are often very supportive of each other (Fage-Butler/Nisbeth Jensen 2012), which raises a question regarding potential bias in answers based on perceptions of what might be the preferred answer to the initial poster's question. I have therefore added Table 1, which includes the questions that initiated the threads and which have been anonymised following the ethical principles outlined above. In all cases, the nature of the responses in the subsequent threads was mixed, with pro- and anti-homebirth arguments, sentiments and accounts of experiences being evident.

I first coded the data using NVivo (QSR International 2015), a software for qualitative data analysis. Coding involved identifying sections of text that revealed some aspect of the construction of the hospitals and labelling these sections. Foucauldian discourse analysis (Andersen 2003; Foucault 1972; Willig 2013) was then used to analyze the constructions of the hospital birth setting in the sections. Foucauldian discourse analysis involves the following three stages (see Willig 2013):

1. Identifying statements that construct the object in question - here, the hospital birth setting. Statements are often a sentence in length, but they can be longer; they are as long as they need to be to construct an aspect of the object in question (Andersen 2003). In other words, when a new aspect is constructed, there is a new statement.

2. Identifying what discourses are reflected in the constructions identified in Stage 1. Statements not only construct an object in a particular way, but they also reflect broader legitimising discourses.

3. Identifying what is achieved by incorporating these constructions. Discourses are used for strategic purposes to promote certain ways of doing and thinking (Foucault 1972).

The constructions of the hospital birth setting are important to map out as they reflect existing meanings circulating in society as well as reproducing them, thereby influencing the culture. From a Foucauldian point of view, discourses outline the limits on the sayable (Foucault 1972; Kendall/Wickham 1999). Mey (2001: 191) sees this as a metapragmatic issue: "discursive space furnishes the metapragmatic wherewithal for the production of meaning", and discourse analysis makes it possible to explore the metapragmatic question of "the circumstances and conditions that allow us to use our language or prevent us from using it" (ibd.: 177). 
However, risk decisions are also deeply personal, reflecting individuals' experiences and preferences (Finkel 2008), and the online data explored here facilitate the identification and analysis of personal as well as more widely distributed discursive meanings. Methodologically, this paper reflects what Benke (2003) describes as the close relationship between applied linguistics (including discourse studies) and cultural studies - for further elaboration of this point, see Barker and Jane (2016) and Barker and Galasinski (2001).

\begin{tabular}{|c|c|c|c|}
\hline $\begin{array}{l}\text { Thread } \\
\text { number }\end{array}$ & $\begin{array}{l}\text { Total } \\
\text { number } \\
\text { of posts in } \\
\text { thread }\end{array}$ & Initial query at head of the thread & $\begin{array}{l}\text { Nature of } \\
\text { responses in } \\
\text { the thread } \\
\text { (positive, } \\
\text { negative or } \\
\text { mixed) }\end{array}$ \\
\hline 1. & 5 & $\begin{array}{l}\text { I do not really like the hospital environment, so I am [...] weighing } \\
\text { up my options. Do the pros outweigh the cons? }\end{array}$ & Mixed \\
\hline 2. & 72 & $\begin{array}{l}\text { I am interested in what other people think of home births, and if } \\
\text { they think midwives are trying to convince more women to have } \\
\text { home births. }\end{array}$ & Mixed \\
\hline 3. & 30 & $\begin{array}{l}\text { For those who have done it or [decided] not to, do the risks out- } \\
\text { weigh the benefits of a home birth? }\end{array}$ & Mixed \\
\hline 4. & 93 & $\begin{array}{l}\text { I have not not put this in the Home birth Group as I wanted a mixed } \\
\text { view from those not considering it too. I am thinking about it as I } \\
\text { hate hospitals [...]. What is your opinion on [this newspaper article } \\
\text { on the risks of home birth]? }\end{array}$ & Mixed \\
\hline 5. & 39 & $\begin{array}{l}\text { How do you all feel about home births? [...] Would you feel safe } \\
\text { [delivering] a baby at home? [...] What do you all think? }\end{array}$ & Mixed \\
\hline 6. & 26 & $\begin{array}{l}\text { I want to know objectively whether a home birth is as safe as a } \\
\text { hospital birth for me and my baby. What is your opinion? }\end{array}$ & Mixed \\
\hline 7. & 49 & $\begin{array}{l}{[\mathrm{T}] \text { here is a }[\ldots] \text { report out today conducted by Oxford University }} \\
{[\ldots] . \text { What is your opinion on this? Would this [study] put you off }} \\
\text { home birth, or do you think [...] other factors are more important? }\end{array}$ & Mixed \\
\hline 8. & 20 & $\begin{array}{l}\text { Has anyone had a similar experience [of shoulder dystocia births]? } \\
\text { I'm worried [consultants] are overly cautious and that this will po- } \\
\text { tentially spoil my birth experience. }\end{array}$ & Mixed \\
\hline 9. & 52 & $\begin{array}{l}\text { In my house, you can hear everything through the walls }[\ldots] \text { So }[\ldots] \\
\text { would this put you off [home birth]? }\end{array}$ & Mixed \\
\hline 10. & 34 & $\begin{array}{l}\text { I am nervous in case there are complications and I am not at hospi- } \\
\text { tal. What would you do? }\end{array}$ & Mixed \\
\hline 11. & 83 & What is your opinion on home births? [...] [Am I] being selfish [...]? & Mixed \\
\hline 12. & 54 & $\begin{array}{l}\text { I would really like a home birth for my second labour }[\ldots] . \text { My other } \\
\text { half disagrees with it and thinks it is dangerous }[\ldots] \text {. What is your } \\
\text { opinion? Would you have a home birth? Is it more dangerous than a } \\
\text { hospital birth? }\end{array}$ & Mixed \\
\hline 13. & 69 & $\begin{array}{l}\text { Have you had, or would you consider a home birth? If you have, } \\
\text { was it an experience you were happy with? }\end{array}$ & Mixed \\
\hline 14. & 31 & $\begin{array}{l}\text { What is your opinion on home birth for the sole reason of having } \\
\text { [had] a [...] quick labour [in a previous birth]? }\end{array}$ & Mixed \\
\hline 15. & 17 & $\begin{array}{l}\text { I have no feelings for or against. [W] hat is your opinion - are home } \\
\text { births an unnecessary risk? }\end{array}$ & Mixed \\
\hline 16. & 332 & $\begin{array}{l}\text { [Is] home birth reckless? [...] I had decided [...] for it. Then I [did an } \\
\text { internet search]. }\end{array}$ & Mixed \\
\hline 17. & 99 & $\begin{array}{l}\text { So what do you think? Have you had home birth, would you like } \\
\text { one, or do you think hospital was the best place for you? }\end{array}$ & Mixed \\
\hline 18. & 57 & $\begin{array}{l}\text { I am considering }[\ldots] \text { home birth }[\ldots] . \text { I }[\ldots] \text { [would like to hear] } \\
\text { [others'] opinions, especially from those that have had them? }\end{array}$ & Mixed \\
\hline
\end{tabular}

Table 1: Overview of threads analysed 


\section{$3 \quad$ Findings}

In the data, few statements provided in answer to the open-ended questions at the head of the thread could be considered neutral, no doubt because the birth setting topic is so polemic (Coxon/Sandall/Fulop 2014; Lupton 2013) and the fact that the data were derived from threads initiated by women facing the birth setting decision who turned to their peers for advice, perspectives and experiences. Table 2, which provides an overview of the initial NVivo (2015) codes (valorised into positives and negatives) and their frequency in the data, i. e. how many sections were associated with each code, helps to indicate the spread. As is evident in Table 2, almost twice as many sections relating to the construction of the hospital birth setting were negatively coded $(\mathrm{N}=196)$ than were positively coded $(\mathrm{N}=114)$.

\begin{tabular}{|l|l|}
\hline $\begin{array}{l}\text { Construction of the hospital as positive: number } \\
\text { of coded text sections }(\mathbf{N}=\mathbf{1 1 4})\end{array}$ & $\begin{array}{l}\text { Construction of the hospital as negative: number } \\
\text { of coded text sections }(\mathbf{N}=\mathbf{1 9 6})\end{array}$ \\
\hline Biomedical expertise at hand $(\mathrm{n}=37)$ & Negative experiences of hospital births $(\mathrm{n}=49)$ \\
\hline Safer $(\mathrm{n}=31)$ & Causes unnecessary interventions $(\mathrm{n}=45)$ \\
\hline Good for complications $(\mathrm{n}=17)$ & Not patient-centered $(\mathrm{n}=37)$ \\
\hline Positive experiences of hospital births $(\mathrm{n}=12)$ & Risky $(\mathrm{n}=35)$ \\
\hline Relaxing, convenient $(\mathrm{n}=8)$ & Negative associations with hospital setting $(\mathrm{n}=19)$ \\
\hline Good for baby $(\mathrm{n}=3)$ & Scary $(\mathrm{n}=8)$ \\
\hline Good for monitoring $(\mathrm{n}=3)$ & For the sick $(\mathrm{n}=3)$ \\
\hline Good for pain relief $(\mathrm{n}=1)$ & \multirow{3}{*}{} \\
\cline { 1 - 1 } Husband an advocate $(\mathrm{n}=1)$ & \\
\cline { 1 - 1 } Respect parents $(\mathrm{n}=1)$ &
\end{tabular}

Table 2: Overview of valorised coded sections (negative and positive)

In what follows, I first present constructions of the hospital birth setting that are positive and that suggest the grounds for women's satisfaction with this choice of birth setting, before presenting posters' negatively valorised constructions of the hospital birth setting which indicate the grounds for their dissatisfaction.

\subsection{Positives of the hospital birth setting}

One of the most recurrent positive constructions of the hospital birth setting is that of added safety achieved through closer proximity to medical practitioners:

(1) There is, of course, a risk in hospital too but it is more likely that you will be able to get treated by a specialist team sooner.

This is supported by narratives where women explain that they and/or their child could have died in childbirth, had they chosen home birth, for example:

(2) My son and I could have died [...] if we had not been in hospital with a brilliant obstetrician and many midwives there at the touch of an emergency button.

The point here is that the risks associated with delayed access to medical specialists and/or equipment can be averted by choosing to give birth at hospital.

Hospitals are constructed as being the safest birth setting in case of medical complications:

(3) I just want to be where help is, if something goes wrong. 
Some posters state that the presence of teams of medical experts and technical equipment in hospitals enhances their satisfaction with the hospital birth setting:

(4) I am all about science, and want the security, sterility, officiousness of the hospital.

(5) Either way, give me doctors and monitors every time!

Due to proximity to doctors and medical equipment in hospitals, hospital obstetric units are constructed as minimising women's stress and promoting well-being:

(6) I prefer a hospital... And I would be more stressed at home.

(7) I was more relaxed in hospital, in the knowledge that all medical interventions were available if needed, than I would have been at home.

Besides the advantages of hospitals for averting calamitous risks during childbirth, hospitals are also appreciated for other advantages such as pain relief, where a medicalised birth is what is desired, for example:

(8) [I] needed to be drugged up [...] to cope, and that was not an option with home birth.

Hospital births are also constructed as leading to positive birthing experiences by some mothers:

(9) I had both mine in hospital and had two great experiences, so I have never really thought about doing it elsewhere.

(10) I had no problems with my [...] birth in hospital. It was lovely.

Hospitals are constructed as being the right or best thing for the baby, though not necessarily for the mother:

(11) Fantastic for my son, but not so much for me.

Hospitals are associated with convenience for the mother:

(12) I like being in hospital, having everything to hand.

Hospitals are also constructed as places where doctors' expertise is judiciously balanced with women's preferences:

(13) I have trust in health professionals to make decisions [...] and ask for my decision when it is a good time for a laywoman to choose.

Being away from one's usual environment is also constructed as an advantage by some of the posters, as it makes birthing more private, as is evident in the following statements:

(14) My eldest saw me laboring at home for a short while and I hated it.

(15) I would need to know I could scream without [people] calling the police as it sounded like I was being murdered.

Considering the constructions above in terms of the discourses that underpin them (Stage 2 of Willig's [2013] approach to Foucauldian discourse analysis, described above), the following discourses are evident: medical expertise (hospitals are the hubs of relevant medical expertise), risk avoidance or mitigation (hospitals help avoid unnecessary risks), moral responsibility (hospitals secure the best outcome for the baby, and are therefore the right choice), and 
patient centeredness (hospitals provide a relaxing, convenient, respectful and private setting for birth). These discourses serve strategic purposes (Stage 3 of Willig's [2013] approach to Foucauldian discourse analysis) in terms of providing legitimation for the choice of the hospital birth setting. They underline the idea that women choosing hospital births do so consciously, reflectively and on their own terms. Choosing hospital as a birth setting is thus not merely a case of choosing the birth setting that has been the approved, de facto choice for many decades: it is a conscious preference and a legitimate choice.

\subsection{Negatives of the hospital birth setting}

As indicated in Table 2, a good deal of the coded sections on the hospital birth setting are negative. Following Willig (2013), statement analysis (Stage 1) reveals that hospitals are constructed as places where health practitioners tend to interpret all births as risky, leading to unnecessary medicalisation of normal birth processes. As such, hospitals are constructed as precipitating increased risks of intervention as well as increased risks of iatrogenic complications associated with interventions. This is expressed via posters' generalisations, accounts of personal experiences, and knowledge of acquaintances' birth experiences, as seen in the following statements:

(16) Pediatricians and obstetricians frequently over-interfere. Because they see so much go wrong, they treat everything like it is going to go wrong also.

(17) I had my first in hospital. It was a drug-fueled assisted delivery due entirely to the treatment I received. I honestly do not think I would have had a traumatic labor/birth had I been at home.

(18) Everyone I know who has had horrible complications has had a hospital birth.

Besides the risks associated with intervention, hospitals are constructed as increasing the medical risks to mother and baby through neglect, poor medical decisions and lack of hygiene:

(19) My best friend was ignored and left with no pain relief, pushing for almost 3 hours. The baby was stuck and they did a cesarean section. They did not stitch her up properly [...]. She had to have a hysterectomy when she was 22 years old because they did so much damage!

(20) I went through my notes with a midwife afterwards, and she was able to pinpoint where things went wrong.

(21) The statistics do not even take into account post-birth infections picked up by grimy hospitals and poor infection control.

Personal neglect also features in women's accounts of their experiences of giving birth at hospital. Instead of providing good medical care, hospitals are negatively associated with experiences of neglect:

(22) If anything was happening to my baby, I would not have known, and the midwives would not have picked it up since they were hardly there. 
(23) My hospital birth was very scary [...]. I was left alone with no support from the people whom I needed to trust. This slowed my labor down and it seemed unbearably painful. I suffered postnatal depression and struggled to bond with my son for months.

Hospitals are also constructed as micromanaging the birth, taking decisions out of women's hands, with resultant disempowerment:

(24) It was horrible. They managed my labor [...] and looking back, none of it was [...] helpful.

(25) I felt like [...] everything [was] happening for the convenience of the hospital.

Hospitals are constructed as not providing patient centred care to women giving birth, resulting in very impersonal experiences around the birth:

(26) I felt like the midwives and consultants [...] did not [...] care about who I was.

(27) I hated every moment of it. I could not relax, and I was surrounded by strangers.

(28) Home birth will be [...] [better] than [...] the hospital conveyor belt.

(29) I was not listened to at all.

The lack of patient centeredness the posters describe is out of step with growing understanding that birthing women should be met with empathy and commitment from medical professionals (Goberna-Tricas et al. 2011).

In a similar vein, hospitals are constructed as not being family-centred, as they split up the family unit at a critical time when the family is being extended and the woman feels vulnerable as family members could not automatically stay, for example, if older children needed to be minded at home:

(30) My husband hated leaving me [for home].

(31) My mother was not even allowed to come into the ward to help me get into bed.

Another prevalent source of dissatisfaction with hospitals as places in which to give birth relates to a general aversion to hospitals. Hospitals are constructed as places to be avoided; in some of the posts, there is considerable antipathy to the idea of hospitals:

(32) I do not associate hospitals with anything good.

(33) I really, really hate hospitals.

Hospitals are constructed as places that instil dread:

(34) Hospitals make me anxious. The idea of giving birth there made me feel really unsettled.

(35) I have a horrible fear of hospital and medical settings. [...] I was way out of my comfort and safety zone.

Hospitals are negatively valorised on the basis of poor experiences of hospital births, including pain and discomfort due to the setting and restrictions in one's movement, tension due to having to be transported to the hospital when in labour, and the association of previous hospital births with the onset of postnatal depression and posttraumatic stress disorder: 
(36) It was uncomfortable. I was tense and could not move around much [...] and [...] it took a lot of pushing to get him out because I was on my back.

(37) Part of the problem last time was to-ing and fro-ing from hospital. It made me anxious and worried.

(38) I am just worried that [...] I will end up with a horrific medicalized birth again, and posttraumatic stress disorder/postnatal depression again.

Hospitals are also constructed as unnatural settings in which to give birth, either due to their lack of homeliness and familiarity, or because of associations with sickness rather than health:

(39) Labor halts when you release adrenaline [...]. So it is not surprising [that] failure to progress or long labor is high in hospitals.

(40) Hospitals are not a natural or homely environment to labor in.

(41) For me, hospitals are for the sick and injured, so I would not feel comfortable giving birth there.

Considering the negative constructions of the hospital birth setting above in relation to the discourses that underpin them (Stage 2 of Willig 2013), hospitals are associated with risk discourses. They are constructed as risky places for birthing women, as they are associated with the risk of interventions, iatrogenic effects of interventions, neglect and lack of sufficient hygiene. The hospital birth setting is also constructed as leading to births that have become unnecessarily medicalised, reflecting the medicalisation discourse (Illich 1974). Such constructions draw on feminist discourses, where women's bodies are constructed as being physically capable of giving birth, and therefore not in need of interventionist, medicalised (and patriarchal) monitoring and procedures around childbirth (see, for example, Barnes 1999). They also reflect discourses of resistance to biopolitics, whereby normal life processes are theorised as having fallen increasingly under state governance (Foucault 2010; Rose 2007; Wilmer/Zukauskaite 2016). The patient centeredness discourse is also present, though it is used to construct hospitals as not providing birthing women with due personal attention or care. The patient empowerment discourse is similarly used to construct hospitals as leading to disempowerment, as medical staff exclude birthing women from decision-making processes. Finally, there is a discourse of fear (Powers 1996) that discursively constructs the hospital setting as terrifying, projecting a phobia of hospitals, also known as nosocomephobia. An overview of the discourses underpinning the positive and negative constructions of the hospital birth setting is presented in Table 3 .

\begin{tabular}{|l|l|}
\hline Positive constructions of hospital birth setting & Negative constructions of hospital birth setting \\
\hline Risk & Risk \\
\hline Biomedical expertise & Medicalisation, feminism, biopolitics \\
\hline Patient centeredness & Lack of patient centeredness \\
\hline Moral responsibility towards the unborn & Lack of patient empowerment \\
\hline & Fear \\
\hline
\end{tabular}

Table 3: Overview of the main discourses underpinning the positive and negative constructions of the hospital birth setting

The negative constructions of this hospital birth setting (Stage 3 of Willig 2013) also serve strategic purposes. Posters who express negative perspectives construct the hospital birth set-

ISSN 1615-3014 
ting in ways that underline its riskiness and lack of patient centeredness. Both in terms of the health and safety of their baby and themselves, as well as their own happiness and wellbeing, the hospital setting is constructed as being deficient, thus delegitimising the choice of hospital as the de facto birth setting, and making room for alternatives.

\section{$4 \quad$ Discussion and conclusion}

The purpose of this study was to uncover discursive constructions of the hospital birth setting from the perspectives of the users, particularly in the light of the recent change to official risk advice regarding birth setting in the UK, where home births, not hospital births, are recommended for low risk deliveries (NICE 2014). The choice of online forum data was motivated by an interest in identifying how peers in an online setting provide each other with support for health-related decisions.

The empirical findings fell into two unequal halves. The tendency to construct the hospital birth setting negatively may reflect counter-hegemonic resistance (Brown 2002; Kelly 2009) to hospital births, where posters see the online forum as an environment where they can express unconventional stances and have an impact on the debate. As Krimsky (2007: 157) notes, "[t]he openness, accessibility and transparency of the Internet will [...] allow consumers to weigh conflicts of interest in risk communication, question authority, and build networks of trust among affinity groups". Despite the faultline noted in the findings, there were significant overlaps in the discourses that were used to construct the hospital setting as either positive or negative: for example, as can be seen from Table 3, a risk discourse underpins both the positive and negative constructions of the hospital birth setting. This reflects the fact that a single discourse can be used to promote opposing strategic purposes (Kelly 2013: 76) and that the discourses that have legitimising potential at any one time and place and for any one field are limited in number. There are other interesting commonalities across the findings. In both sets of findings, women express the need to be respected. They want to do the right thing and are keen to construct their views on the hospital birth setting as morally justified - both in relation to themselves and their babies. They also want the birthing experience to be positive. The most striking differences relate to the concepts of risk and autonomy. For some women, going to hospital is the risky choice, while for others, not going to hospital is deemed risky. It is essential for some women to feel empowered and have their needs respected and met in the birthing situation, while others are more inclined to downplay this need, prioritising instead the proximity of medical expertise in case the unexpected happens.

The empirical findings presented in this paper are valuable as they reflect current sociocultural meanings regarding the hospital birth setting. It is important that medical practitioners and maternity staff are aware of these, although the British context needs to be borne in mind in relation to the generalisability of the findings. From a patient centred perspective, it is essential to establish what each individual wants (Holmström/Röing 2010; Mead/Bower 2000). However, knowing the kinds of arguments to which individuals have potentially been exposed can help to inform medical staff's discussions with pregnant women regarding birth setting, sensitising them to women's likely concerns and preferences. In this way, practitioners' knowledge of the cultural terms of the debate can help to improve women's satisfaction with maternity services. 
Methodologically, the constructivist approach used in this paper was valuable as it provided insights into valorised constructions of the hospital birth setting and their underpinning legitimising discourses. In highlighting the metapragmatic meanings that set boundaries on the terms of the debate (public and private), this paper demonstrates the value of a discursive approach to the study of the cultural frames within which birth setting decisions are made. I would argue that other health-related topics of a sensitive or polemic nature could also benefit from a research design similar to the present where online data that include emic perspectives and are handled ethically are combined with a discourse analytical methodology. The discourse analytical approach also had its blind spots, however. An important follow-up study would be to examine similar data from another perspective, particularly using interpersonal pragmatics (Locher/Graham 2010), to see how agreements and disagreements are negotiated online, as well as how the affordances of the online setting are interactively employed in online discussions on such a very polarised topic.

As previously noted, the concept of satisfaction with medical care has been criticised as being fuzzy and in need of theoretical development and critical review (e. g. Sawyer et al. 2013; Turris 2005). In identifying the grounds for satisfaction and dissatisfaction with the hospital birth setting, this paper brings a social constructionist ontology and discourse analytical methodology to the study of satisfaction and dissatisfaction with healthcare provision. The inductive approach adopted in this paper can support future theory development, as the findings from this paper could form the basis of a study specifically on (dis)satisfaction with the hospital birth setting where women, perhaps as part of an interview study, are asked to reflect on some of the quotations from posters in this study that reflect both the perceived positives and negatives of the hospital birth setting. The fact that women have previously made negative statements about the hospital birth setting provides these statements with legitimacy that could potentially promote more open discussions of (dis)satisfaction with the hospital birth setting, which would be valuable given concerns about possible over-reporting of satisfaction, noted earlier. If the negative view of hospital births, which weighed more heavily than the positive view in this study, actually reflects more generally women's experiences of hospital births, then it seems that there is considerable room for improvement in the medical and personal care that birthing women receive at hospitals. Further research is needed in this area.

Finally, this study illustrates how the online setting supports patient 2.0 empowerment (van Uden-Kraan et al. 2008; Bos et al. 2008) where the empowerment that takes place is horizontal (peer-peer) rather than vertical (peer-expert). It illustrates how the online setting supports individuals taking the birth setting decision, as posters respond to requests for perspectives and advice using narratives, anecdotes, stated views and arguments that discursively construct the hospital obstetric unit either as a desirable or undesirable birth setting. In this way, women faced with the morally charged birth setting decision are provided with pros and cons of the hospital setting for further deliberation. 


\section{References}

Akrich, Madeleine/Leane, Máire/Roberts, Celia/Nunes, João Arriscado (2014): "Practising childbirth activism: A politics of evidence”. BioSocieties 9/2: 129-152. doi: 10.1057/ biosoc.2014.5.

Andersen, Niels Åkerstrøm (2003): Discursive Analytical Strategies: Understanding Foucault, Koselleck, Laclau, Luhmann. Bristol: The Policy Press.

Andrews, Gavin J. (2016): "Geographical thinking in nursing inquiry, part one: Locations, contents, meanings". Nursing Philosophy 17/4: 262-281. doi: 10.1111/nup.12133.

Armstrong, Elizabeth Mitchell (2010): "Home birth matters - For all women". The Journal of Perinatal Education 19/1: 8-11. doi: 10.1624/105812410X482329.

Barker, Chris/Jane, Emma A. (2016): Cultural Studies: Theory and Practice. $5^{\text {th }}$ edition. London: Sage.

Barker, Christopher/Galasinski, Dariusz (2001): Cultural Studies and Discourse Analysis: A Dialogue on Language and Identity. London: Sage.

Barnes, Margaret (1999): "Research in midwifery - The relevance of a feminist theoretical framework". Australian College of Midwives Incorporated Journal 12/2: 6-10. doi: 10.1016/S1031-170X(99)80013-0.

Bélanger-Lévesque, Marie-Noëlle/Pasquier, Marilou/Roy-Matton, Naomé/Blouin, Simon/Pasquier, Jean-Charles (2014): "Maternal and paternal satisfaction in the delivery room: A cross-sectional comparative study". BMJ Open 4/2. doi: 10.1136/bmjopen-2013004013.

Benke, Gertraud (2003): “Applied linguistics: A science of culture?”. Linguistik Online 14/2. doi: 10.13092/lo.14.822.

Bos, Lodewijk/Marsh, Andy/Carroll, Denis/Gupta, Sanjeev/Rees, Mike (2008): "Patient 2.0 empowerment". In: Arabnia, Hamid R./Marsh, Andy (eds.): Proceedings of the 2008 International Conference on Semantic Web \& Web Services SWWSO8. Las Vegas, CSREA Press: $164-167$.

Brailey, Sue/Jarrett, Patricia/Luyben, Ans/Poat, Angela (2015): "Swimming against the tide: Women's experience of choosing a homebirth in Switzerland". British Journal of Midwifery 23/11: 780-788. doi: 10.12968/bjom.2015.23.11.780.

British Psychological Society (2013): Ethics Guidelines for Internet-Mediated Research. Leicester: British Psychological Society.

Brocklehurst, Peter/Hardy, Pollyanna/Hollowell, Jennifer/Linsell, Louise/Macfarlane, Alison/McCourt, Christine/Marlow, Neil/Miller, Alison/Newburn, Mary/Petrou, Stavros/Puddicombe, David/Redshaw, Maggie/Rowe, Rachel/Sandall, Jane/Silverton, Louise/Stewart, Mary (2011): "Perinatal and maternal outcomes by planned place of birth for healthy women with low risk pregnancies: The birthplace in England national prospective cohort study". British Medical Journal 343/7840: d7400. doi: 10.1136/bmj.d7400.

Brown, Anna (2002): "Foucauldian perspectives on midwifery practices and education". The Internet Journal of Advanced Nursing Practice 6/1: s. p.

Burges Watson, Duika/Murtag, Madelaine J./Lally, Joanne E./Thomson, Richard J./McPhail, Sheila (2007): "Flexible therapeutic landscapes of labour and the place of pain relief". Health \& Place 13/4: 865-876. doi: 10.1016/j.healthplace.2007.02.003. 
Caron-Flinterman, J. Francisca/Broerse, Jacqueline E. W./Bunders, Joske F. G. (2005): “The experiential knowledge of patients: A new resource for biomedical research?". Social Science \& Medicine 60: 2575-2584. doi: 10.1016/j.socscimed.2004.11.023.

Cohen, Jodi H./Raymond, Jennifer M. (2011): "How the internet is giving birth (to) a new social order". Information, Communication \& Society 14/6: 937-957. doi: 10.1080/ 1369118X.2011.582132.

Collins, Melinda/Shattell, Mona/Thomas, Sandra P. (2005): "Problematic interviewee behaviors in qualitative research". Western Journal of Nursing Research 27/2: 188-199. doi: $10.1177 / 0193945904268068$.

Coulson, Neil (2015): Online Research Methods for Psychologists. London: Palgrave.

Coxon, Kirstie (2014): "Risk in pregnancy and birth: Are we talking to ourselves?". Health, Risk \& Society 16/6: 481-493. doi: 10.1080/13698575.2014.957262.

Coxon, Kirstie/Sandall, Jane/Fulop, Naomi J. (2014): "To what extent are women free to choose where to give birth? How discourses of risk, blame and responsibility influence birth place decisions". Health, Risk \& Society 16/1: 51-67. doi: 10.1080/ 13698575.2013.859231.

de Crespigny, Lachlan/Savulescu, Julian (2014): "Homebirth and the future child". Journal of Medical Ethics 40/12: 807-812. doi: 10.1136/medethics-2012-101258.

Department of Health (2013): Maternity Services in England. London: The Stationery Office. www.nao.org.uk/wp-content/uploads/2013/11/10259-001-Maternity-Services-Book-1.pdf [28.02.2017].

Fage-Butler, Antoinette Mary/Jensen, Matilde Nisbeth (2012): "The interpersonal dimension of online patient forums: How patients manage informational and relational aspects in response to posted questions". Hermes 51: 21-38.

Finkel, Adam F. (2008): “Perceiving others' perceptions of risk: Still a task for Sisyphus”. In: Tucker, W. Troy/Ferson, Scott (eds.): Strategies for Risk Communication: Evolution, Evidence, Experience. Boston, Blackwell: 121-137.

Foucault, Michel (1972): The Archaeology of Knowledge. New York: Pantheon.

Foucault, Michel (2010): The Birth of Biopolitics: Lectures at the Collège de France, 19781979. Basingstoke: Palgrave Macmillan.

Gesler, Wilbert M. (1992): The Cultural Geography of Health Care. Pittsburgh: University of Pittsburgh Press.

Goberna-Tricas, Josefina/Banús-Giménez, Marìa Rosa/Palacio-Tauste, Alicia/LinaresSancho, Sara (2011): "Satisfaction with pregnancy and birth services: The quality of maternity care services as experienced by women". Midwifery 27/6: e231-e237. doi: 10.1016/ j.midw.2010.10.004.

Holmström, Inger/Röing, Marta (2010): "The relation between patient-centeredness and patient empowerment: A discussion on concepts". Patient Education and Counseling 79/2: 167-172. doi: 10.1016/j.pec.2009.08.008.

Illich, Ivan (1974): Medical Nemesis. London: Calder \& Boyars.

Jha, Ashish K./Orav, E. John/Zheng, Jie/Epstein, Arnold M. (2008): "Patients' perception of hospital care in the United States". New England Journal of Medicine 359/18: 1921-1931. doi: 10.1056/NEJMsa0804116. 
Jones, Rodney (2013): Health and Risk Communication: An Applied Linguistic Perspective. London: Routledge.

Kelly, Mark G. E. (2009): The Political Philosophy of Michel Foucault. Abingdon: Routledge.

Kelly, Mark G. E. (2013): Foucault's History of Sexuality Volume 1, The Will to Knowledge. Edinburgh: Edinburgh University Press.

Kendall, Gavin/Wickham, Gary (1999): Using Foucault's Methods. London: Sage.

Kenkmann, Andrea/Poland, Fiona/Burns, Diane/Hyde, Paula/Killett, Anne (2017): "Negotiating and valuing spaces: The discourse of space and 'home' in care homes". Health \& Place 43: 8-16. doi: 10.1016/j.healthplace.2016.11.006.

Kouper, Inna (2010): “The pragmatics of peer advice in a live journal community". Language@Internet 7: article 1.

Krimsky, Sheldon (2007): "Risk communication in the internet age: The rise of disorganized skepticism”. Environmental Hazards 7/2: 157-164. doi: 10.1016/j.envhaz.2007.05.006.

Krumpal, Ivar (2013): "Determinants of social desirability bias in sensitive surveys: A literature review”. Quality \& Quantity 47/3: 2025-2047. doi: 10.1007/s11135-011-9640-9.

Locher, Miriam A. (2010): "Health internet sites: A linguistic perspective on health advice columns". Social Semiotics 20/1: 43-59. doi: 10.1080/10350330903438402.

Locher, Miriam A./Graham, Sage L. (2010): "Introduction to interpersonal pragmatics". In: Locher, Miriam A./Graham, Sage L. (eds.): Interpersonal Pragmatics. Berlin, Mouton de Gruyter: 1-13.

Lupton, Deborah (2013): The Social Worlds of the Unborn. New York: Palgrave Macmillan.

Maehara, Kunie/Mori, Emi/Tsuchiya, Miyako/Iwata, Hiroko/Sakajo, Akiko/Tamakoshi, Koji (2016): "Factors affecting maternal confidence and satisfaction in older Japanese primiparae during postpartum hospital stay". International Journal of Nursing Practice 22/S1: 1421. doi: 10.1111/ijn.12435.

Mahon, Pamela Young (1996): "An analysis of the concept 'patient satisfaction' as it relates to contemporary nursing care”. Journal of Advanced Nursing 24/6: 1241-1248.

Majchrzak, Ann/Faraj, Samer/Kane, Gerald C./Azad, Bijan (2013): "The contradictory influence of social media affordances on online communal knowledge sharing". Journal of Computer-Mediated Communication 19/1: 38-55. doi: 10.1111/jcc4.12030.

Mead, Nicola/Peter Bower (2000): "Patient-centeredness: A conceptual framework and review of the empirical literature". Social Science \& Medicine 51/7: 1087-1110. doi: 10.1016/S0277-9536(00)00098-8.

Mey, Jacob L. (2001): Pragmatics: An Introduction. $2^{\text {nd }}$ edition. Oxford: Blackwell.

Morrow, Phillip R. (2006): "Telling about problems and giving advice in an internet discussion forum: Some discourse features". Discourse Studies 8/4: 531-548. doi: 10.1177/ 1461445606061876.

NICE (2014): "Intrapartum care for healthy women and babies". www.nice.org.uk/ guidance/CG190 [01.03.2017].

Nolan, Mary (2015): "Perceptions of risk: How they influence women's and health professionals' choices”. British Journal of Midwifery 23/8: 547-551. doi: 10.12968/ bjom.2015.23.8.547. 
QSR International (2015): NVivo (Version 11.1.0) [computer software] www.qsrinterna tional.com/nvivo/home.

Powers, Penny (1996): "Discourse analysis as a methodology for nursing inquiry". Nursing Inquiry 3/4: 207-217. doi: 10.1111/j.1440-1800.1996.tb00043.x.

Redshaw, Maggie (2008): "Women as consumers of maternity care: Measuring 'satisfaction' or 'dissatisfaction'?”. Birth 35/1: 73-76. doi: 10.1111/j.1523-536X.2007.00215.x.

Reyniers, Thijs/Houttekier, Dirk/Cohen, Joachim/Pasman, H. Roeline/Deliens, Luc (2014): "The acute hospital setting as a place of death and final care: A qualitative study on perspectives of family physicians, nurses and family carers". Health \& Place 27: 77-83. doi: 10.1016/j.healthplace.2014.02.002.

Rose, Nikolas (2007): The Politics of Life itself: Biomedicine, Power, and Subjectivity in the Twenty-First Century. Princeton/NJ: Princeton University Press.

Sawyer, Alexandra/Rabe, Heike/Abbott, Jane/Gyte, Gillian/Duley, Lelia/Ayers, Susan (2013): "Parents' experiences and satisfaction with care during the birth of their very preterm baby: A qualitative study". BJOG: An International Journal of Obstetrics \& Gynaecology 120/5: 637-643. doi: 10.1111/1471-0528.12104.

Srivastava, Aradhana/Avan, Bilal I/Rajbangshi, Preety/Bhattacharyya, Sanghita (2015): “Determinants of women's satisfaction with maternal health care: A review of literature from developing countries". BMC Pregnancy and Childbirth 97/15. doi: 10.1186/s12884-0150525-0.

Striley, Katie/Field-Springer, Kimberly (2016): "When it's good to be a bad nurse: Expanding risk orders theory to explore nurses' experiences of moral, social and identity risks in obstetrics units". Health, Risk \& Society 18/1-2: 77-96. doi: 10.1080/13698575.201 6.1169254.

Truijens, Sophie E. M./Pommer, Antoinette M./van Runnard Heimel, Pieter/Verhoeven, Corine J. M./ Oei, S. Guid/Pop, Victor J. M. (2014): “Development of the pregnancy and childbirth questionnaire (PCQ): Evaluating quality of care as perceived by women who recently gave birth". European Journal of Obstetrics \& Gynecology and Reproductive Biology 174: 35-40. doi: 10.1016/j.ejogrb.2013.11.019.

Turris, Sheila A. (2005): "Unpacking the concept of patient satisfaction". Journal of Advanced Nursing 50/3: 293-298. doi: 10.1111/j.1365-2648.2005.03392.x.

van Teijlingen, Edwin R./Hundley, Vanora/Rennie, Ann-Marie/Graham, Wendy/Fitzmaurice, Ann (2003): "Maternity satisfaction studies and their limitations: 'What is, must still be best'”. Birth 30/2: 75-82. doi: 10.1046/j.1523-536X.2003.00224.x.

van Uden-Kraan, Cornelia F./Drossaert, Constance H. C./Taal, Erik/Shaw, Bret R./Seydel, Erwin R./van de Laar, Mart A. F. J. (2008): "Empowering processes and outcomes of participation in online support groups for patients with breast cancer, arthritis, or fibromyalgia”. Qualitative Health Research 18/3: 405-417. doi: 10.1177/1049732307313429.

Willig, Carla (2013): Introducing Qualitative Research in Psychology. $3^{\text {rd }}$ edition. Maidenhead: Open University Press.

Wilmer, S.E./Zukauskaite, Audrone (eds.) (2016): Resisting Biopolitics: Philosophical, Political, and Performative Strategies. Abingdon: Routledge. 
Wood, Rebecca J./Mignone, Javier/Heaman, Maureen I./Robinson, Kristine J./Stieber Roger, Kerstin (2016): “Choosing an out-of-hospital birth centre: Exploring women's decisionmaking experiences". Midwifery 39: 12-19. doi: 10.1016/j.midw.2016.04.003.

Zielinski, Ruth/Ackerson, Kelly/Low, Lisa Kane (2015): "Planned home birth: Benefits, risks, and opportunities". International Journal of Women's Health 7: 361-377. doi: 10.2147/ IJWH.S55561.

\section{Bionote}

Antoinette Fage-Butler holds a PhD in Knowledge Communication from Aarhus University, Denmark, where she is currently an associate professor in the Department of English. Her research interests include online health communication (doctor-patient and patientpatient, and digital health), improving quality in texts for patients, women's health issues, risk communication and ethical aspects of health communication. Focus on the patient perspective permeates her research. Methodologically, she has contributed to poststructuralist approaches to discourse and has collaborated internationally on critical genre analysis. 